\title{
Inhibitive effect of artemisia judaica extract as green corrosion inhibitor for carbon steel in sulfuric acid solution
}

\begin{abstract}
The influence of Artimisia Judaica extract as corrosion inhibitor for carbon steel (CS) in $0.5 \mathrm{~mol} \mathrm{~L}^{-1}$ sulfuric acid has been given by employing some electrochemical and chemical methods. The examination of CS surface was tested. The rate of corrosion was break down by $91 \%$ as the dose of Artimisia Judaica rise to $300 \mathrm{ppm}$. The influence of the temperature in the range of 25 to $45^{\circ} \mathrm{C}$ was studied. Parameters of thermodynamic were measured among the performance of the excellent adsorption fitting isotherm. The extract compounds were adsorbed on CS surface following Langmuir adsorption isotherm. The potentiodynamic polarization (PP) data indicated that this extract plays as mixed-type inhibitor. The addition of extract rise the $\left(\mathrm{R}_{\mathrm{ct}}\right)$ charge transfer resistance and lower the $\left(\mathrm{C}_{\mathrm{d}}\right)$ capacitance of the double layer. The film coated on a CS sample and surface analysis was obtained utilizing (SEM) scanning electron microscope, (FTIR) Fourier transform infrared spectroscopy and (AFM) atomic force microscopy analysis.
\end{abstract}

Keywords: A. judaica, corrosion inhibition, chemical techniques, electrochemical techniques, adsorption, sulfuric acid
Volume 2 Issue 7 - 2017

AS Fouda, K Shalabi, A Alsadeag

Department of Chemistry, Mansoura University, Egypt

Correspondence: AS Fouda, Department of Chemistry, Mansoura University, Egypt, Tel +2 050 2365730, Fax +2 050 220227I,Email asfouda@hotmail.com

Received: April 28, 2017 | Published: September 06, 2017

\section{Introduction}

The corrosion definition is not constrained to alloy and metals, but rather the term, corrosion, can likewise be stretched out to earthenware production and other nonmetallic materials. Corrosion can prompt to problems significant in furthest fields for man-factory. ${ }^{1}$ Corrosion gets to be distinctly a standout amongst the most difficult points for researchers and the society for building. From the stance of the significance of alloy in manufacture, $\mathrm{CS}$ is choice among the metal of because of its unmistakable attributes and wide application side. In a few man-factory procedures, for example, corrosive cleaning, corrosive well acidizing, and acidic pickling, rust and polluted scales were generally evacuated utilizing acidic medium. In the pickling procedures of metals sulfuric and hydrochloric acids are the most generally utilized. As a result of the general dangerous assault of acidic corrosive medium, the inhibitors utilization to control the forcefulness of acidic corrosive condition was found to have across the board utilized in numerous industry. ${ }^{2}$ The practicality of insurance strategies rely predominantly on the process of encompassing environment that materials, especially metals, experienced during service conditions. The utilization of inhibitor to limit rate of corrosion in system closed service is well-based and accepted continually. ${ }^{3-7}$ In research, many organic assembled have been noted as corrosion potential inhibitor for various metals, but on the other side, ecological and healthy problems have been arisen because of utilized such synthetic assembled. In like manner, naturally take place substances, for example, plant extract can be utilized as options. ${ }^{8-14}$ The utilization of the plant extracts as potential specialists to lessen consumption in different regular mechanical arrangements. Inhibitors from plant concentrates are renewable, promptly accessible, and satisfactory and earth inviting. The utilization extracts as potential versus to lower corrosion in unlike typical industrial. Plant extracts are assets renewable for inhibitors, the target from paper are utilized an aqueous extract readying from the Artimisia Judaica, as inhibitor to minimize the corrosion habit of CS in solutions of sulfuric acid.

\section{Materials and techniques}

\section{Samples}

The CS utilized in the present paper was obtained from Fields Company for Petrobel. The chemical composition of the material (weight \%) is as; (0.003) Si, (0.20) C, (0.025) P, (0.35) Mn and the rest iron. For (MR) tests, sheet of CS (measured $20 \mathrm{mlx} 20 \mathrm{mlx} 1 \mathrm{ml}$ ) was abraded with different grades of emery papers, washed by bi-distilled water, acetone, dried and then weighed. Hooks made from glass were utilized to hold the coins in the testing solutions under the corrosive medium surface by $1 \mathrm{~cm}$.

\section{Solutions}

The test solution was $\mathrm{H}_{2} \mathrm{SO}_{4}(0.5 \mathrm{M})$. From Al-Gomhoria Company, Egypt the sulfuric acid $(98 \%$, specific gravity=1.84) had been purchased. $100 \mathrm{ml}$ of solutions of $\mathrm{H}_{2} \mathrm{SO}_{4}$ was utilized as testing solution and prepared freshly before each test. Also, bi-distilled water was utilized for the preparation of acidic solution.

\section{Preparation of plant extract}

The collected aerial parts of Plant A. Judaica from the Region ElArish of the Peninsula Sinai, Egypt and shade at room temperature and grind using electrical mill into fine powder, then take $10 \mathrm{~g}$ of powder in $500 \mathrm{ml}$ measuring flask and dissolved it in bi-distilled water and leave the flask on the hot plate, after that the solution leave too cool at room temperature then filtrate. Take $10 \mathrm{ml}$ filtrate $+5 \mathrm{ml}$ ethanol in condensate-collecting flask of rotary evaporator to determine concentration of dissolved substance in plant extract solution. The extract was dried and refrigerating keeping at $5^{\circ} \mathrm{C}$, over needed for the tests. $1000 \mathrm{mg} \mathrm{L}^{-1}$ stock solutions were obtained by dissolving one gram of the extract in bi-distilled water and complete to $1000 \mathrm{ml}$. The doses of the plant extract range from $50 \mathrm{mg} \mathrm{L}^{-1}$ to $300 \mathrm{mg} \mathrm{L}^{-1}$. Table 1 recorded phytochemical bioactive extract of A. Judaica. One sesquiterpene lactone, vulgarin (1); three terpenoidal 
compounds, taraxerol acetate (2), $\beta$-amyrin (3), and lupeol (4); one sterol, $\beta$-sitosterol (5), in addition to a flavone aglycone, lutoelin3'-methyl ether ( 6 ), and its glycoside, luteolin 3'-methyl ether-7glucoside (7); two polymethoxy flavones, luteolin-6, 7, 4'-trimethyl ether (8) and artemetin (9), were identified. Characterization of these compounds Table 1 was achieved through their chemical, chromatographic, physical and spectral tests (MS, UV, 13 C NMR and $1 \mathrm{H}$ NMR). The analytical values were in agreement with reported in the literatures. ${ }^{15}$

Table I The isolated extract A. Judaica constituents

\section{Chemical constituents of $A$. judaica extract}<smiles>CC1C(=O)OC2C1CCC1(C)C(=O)C=CC(C)(O)C21</smiles><smiles>COC1CCC2(C)C3CCC4(C)C(CCC5(C)CCC4(C)CC5)C3CCC2C1(C)C</smiles><smiles>C=C(C)C1CCC2(C)CCCC1C2C1CCC2CC1CCC2(C)C</smiles>

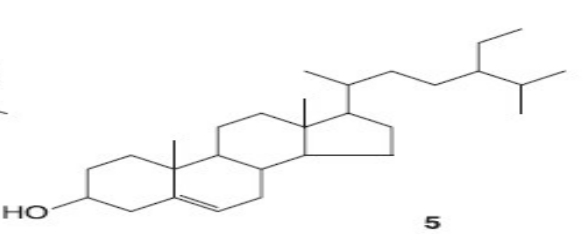<smiles>C=C1C(=O)Oc2cc(OC)c(Br)c(O)c2C1=O</smiles>

$\begin{array}{cccccc}\text { Compound } & \mathbf{R} & \mathrm{R}^{1} & \mathrm{R}^{1} & \mathrm{R}^{3} & \mathbf{R}^{4} \\ \mathbf{6} & \mathrm{H} & \mathrm{H} & \mathrm{H} & \mathrm{CH}_{3} & \mathrm{H} \\ \mathbf{7} & \mathrm{H} & \mathrm{H} & \mathrm{Glc} & \mathrm{CH}_{3} & \mathrm{H} \\ \mathbf{8} & \mathrm{H} & \mathrm{OCH}_{3} & \mathrm{CH}_{3} & \mathrm{H} & \mathrm{CH}_{3} \\ \mathbf{9} & \mathrm{OCH}_{3} & \mathrm{OCH}_{3} & \mathrm{CH}_{3} & \mathrm{CH}_{3} & \mathrm{CH}_{3}\end{array}$

Chemical structures of the isolated compounds from Artemisia judaica aerial parts.

\section{Mass reduction (MR) tests}

The CS coins surface were scratching, to a finish mirror surface, utilized various grades of paper emery began with kind coarser 80 to smooth one 1200 , bi-distilled water rinsed and dried gently utilized filter papers. The procedure for (MR) as follows; first, the coins was weighted by utilized electronic balance with a higher sensitive and then the coins were dipped into $100 \mathrm{ml}$ of solution $0.5 \mathrm{~mol} \mathrm{~L}^{-1} \mathrm{H}_{2} \mathrm{SO}_{4}$ in existence and lack of unlike dose of A. Judaica extract at $30^{\circ} \mathrm{C}$. For (MR) test, the intervals time were ( 0.5 to 3 hour). After each time, the tested coins were exited from the solution, rinsed with bi-distilled water, dried and re-weighted again and listed. The rate of corrosion $\left(\mathrm{C}_{\mathrm{R}}\right)$ was measured from the data of (MR) divided by time (min) and the total surface area $\left(\mathrm{cm}^{2}\right)$.

\section{Electrochemical tests}

Three various electrochemical tests were obtain utilized three electrode arranged in a cell from glass as follows; (WE) working electrode CS coins, (SCE) saturated calomel play as electrode reference, and Pt wire as an electrode auxiliary. In the present paper, the WE was obtain of squared coins of CS from one side were welded with rod of copper. The electrode reference was related to a capillary Luggin. All the tests were found were stagnant conditions subjected. Before began electrochemical tests, the WE was readying in the same manner of (MR) tests and the potential electrode for 25 min stabilized. All results from electrochemical have given by utilized Instrument
Gamry (PCI4/750) system contain software DC105 for EFM140 for EFM tests, PP tests and software EIS300 for EIS (AC). In appending, software Echem 6.03 was utilized for fitting value, drawing and graphing.

\section{PP tests}

PP diagrams given from Tafel polarization by changing the potential of working electrode automatically from -1000 to $0 \mathrm{mV}$ with a rate of scan of $1 \mathrm{mVs}^{-1}$ from at open potential circuit. The current corrosion was measured by the Tafel lines (cathodic and anodic) ( $\beta$ c and $\beta_{\mathrm{a}}$ ) to gives $\log \mathrm{i}_{\text {corr }}$ and $\left(\mathrm{E}_{\text {corr }}\right)$. The protection efficiency ( $\%$ IE) and $(\theta)$ were measured utilized the given data of $i_{\text {corr }}$

\section{EIS tests}

EIS tests were occurred at OCP and were carried out in the frequency range $10^{5}-10^{-1} \mathrm{~Hz}$, and the $\mathrm{AC}$ signal was $0.005 \mathrm{~V}$ in amplitude. EIS diagrams are given in the Nyquist and Bode representations. Equivalent Circuit was utilized to fit the impedance data.

\section{EFM tests}

A frequency of two varies 2 and $5 \mathrm{~Hz}$ with frequency base $=0.1 \mathrm{~Hz}^{16}$ was performance to give the EFM. It is insistent form data of minimum frequency not stronger than a half of the maximum frequency. The frequency maximum must also be lower enough that the double layer charging does not to the current contribute response. The maximum 
peaks function to measure the causality factors corresponding [CF-2 and $\mathrm{CF}-3],\left(\beta_{\mathrm{a}}\right.$ and $\left.\beta_{\mathrm{c}}\right)$ and $\left(\mathrm{i}_{\text {corr }}\right)$.

\section{Surface analysis}

Three CS coins of area $=(20 \mathrm{ml} \times 20 \mathrm{ml} \times 1 \mathrm{ml})$ were utilized in this tests, the first coins of CS was utilized to analyze the surface of CS nonexistence neither acid exposure nor extract treatment, the second coins was dipped completely for 12 hours into the blank $\left(0.5 \mathrm{~mol} \mathrm{~L}^{-1}\right.$ $\mathrm{H}_{2} \mathrm{SO}_{4}$ ) and exposure lake to plant extract. The last coins of metal were inundation for 12 hours in a solution test of $0.5 \mathrm{~mol} \mathrm{~L}^{-1} \mathrm{H}_{2} \mathrm{SO}_{4}$ including $300 \mathrm{mg}^{-1} \mathrm{~L}^{-1}$ of A. Judaica extract. The surface were tested utilized (SEM, JOEL, JSM-T20, Japan).

\section{Atomic force microscopy (AFM)}

AFM is a process powerful for roughness crowd value from a surfaces verity and insight direct into the exchanges in the shape of surface occurred at several nanometers hundred when topographical exchanges because the begin of formation and corrosion of film covered on the CS in the attendance of extract A. Judaica. The size examination of all the AFM picture at a rate of scan of 2.4 lines per second

\section{FTIR Spectra}

The composition of the product form corrosion on the CS surface was examined by FTIR spectroscopic study. IR Affinity (PerkinElmer) spectrophotometer was used for recording the FTIR spectra of the copper plate and lupine extract (crude) at central laboratory in faculty of pharmacy Mansoura University. A range of frequency = $4000-400 \mathrm{~cm}^{-1}$ was utilized.

\section{Results and discussion}

\section{MR tests}

MR was measured after equal interval time of immersion into the test solution of $0.5 \mathrm{~mol} \mathrm{~L}^{-1} \mathrm{H}_{2} \mathrm{SO}_{4}$ nonexistence and existence of unlike dose of the investigated extract. Figure 1 plots for systems contain extract fall below of the acidic free. This led to the CS is a function of both the kind and the additive dose. The $(\theta)$, similar, the protection efficiency improve when the additive plant dose rise and MR was occurs dropped, while the protection efficiency break down as temperature rise, this can illustrated the physical adsorption formed on the surface of CS by the plant extract constituents. Table 2 recorded $(\% \mathrm{IE})$ and $(\theta)$ given from MR measured. The outcome data were analyzed from Eq. (1):

$$
\% \text { I.E }=\mathrm{Cx} 100=100 x\left[\left(\mathrm{C}_{\mathrm{R}}{ }^{\prime}-\mathrm{C}_{\mathrm{R}}\right) / \mathrm{C}_{\mathrm{R}}{ }^{\prime}\right.
$$

$\mathrm{C}_{\mathrm{R}}, \mathrm{C}_{\mathrm{R}}$ the rates of corrosion nonexistence and existence of extract A. Judaica, continually.

\section{Adsorption isotherm}

The research of corrosion protection process was fitting to adsorption Langmuir obtains in next:

$$
\mathrm{C} / \theta=\mathrm{C}+1 / \mathrm{k}_{\mathrm{ads}}
$$

Where, $\mathrm{C}=$ plant extract dose of the inhibitor and $\mathrm{K}_{\mathrm{ads}}=$ constant equilibrium of adsorption belong $\Delta \mathrm{G}^{\circ}$ ads by eqn.3:

$$
\mathrm{K}_{\text {ads }}=1 / 5.55 \mathrm{e}^{\left(-\Delta \mathrm{G}^{\circ} \mathrm{ads} / \mathrm{RT}\right)}
$$

Straight lines given when drawing $\mathrm{C}$ vs. $\mathrm{C} / \theta$ for A. Judaica appending adsorption on the CS surface of sulfuric acid at $25^{\circ} \mathrm{C}$ is obtain in Figure 2 and thermodynamic adsorption have and listed measured in Table 3. The -ve sign of $\Delta \mathrm{G}^{\circ}{ }_{\text {ads }}$, in other hand, improving when temperature improve. The adsorption takes place by the electrostatic attraction and spontaneous process. The analyses for the given data of $\Delta \mathrm{G}^{\circ}$ ads were lower negative than $-20 \mathrm{~kJ} \mathrm{~mol}^{-1}$ led to that the process of adsorption of the extract on CS in $0.5 \mathrm{~mol} \mathrm{~L}^{-1}$ $\mathrm{H}_{2} \mathrm{SO}_{4}$ solution is physisorption. ${ }^{17} \mathrm{The}\left(\Delta \mathrm{H}^{\circ}{ }_{\text {ads }}\right)$ could be measured by equation Van't Hoff:

$$
\log \mathrm{K}_{\mathrm{ads}}=\left(-\Delta \mathrm{H}_{\text {ads }}^{\circ} / 2.303 \mathrm{RT}\right)+\text { constant }
$$

Figure 3 plot $1 / \mathrm{T}$ against $\log \mathrm{K}_{\text {ads }}$ for measure $\left(\Delta \mathrm{H}_{\text {ads }}^{\circ}\right)$. From the diagrams given slope $=\left(-\Delta \mathrm{H}^{\circ}\right.$ ads $\left./ 2.303 \mathrm{RT}\right)$. In suitable by the next:

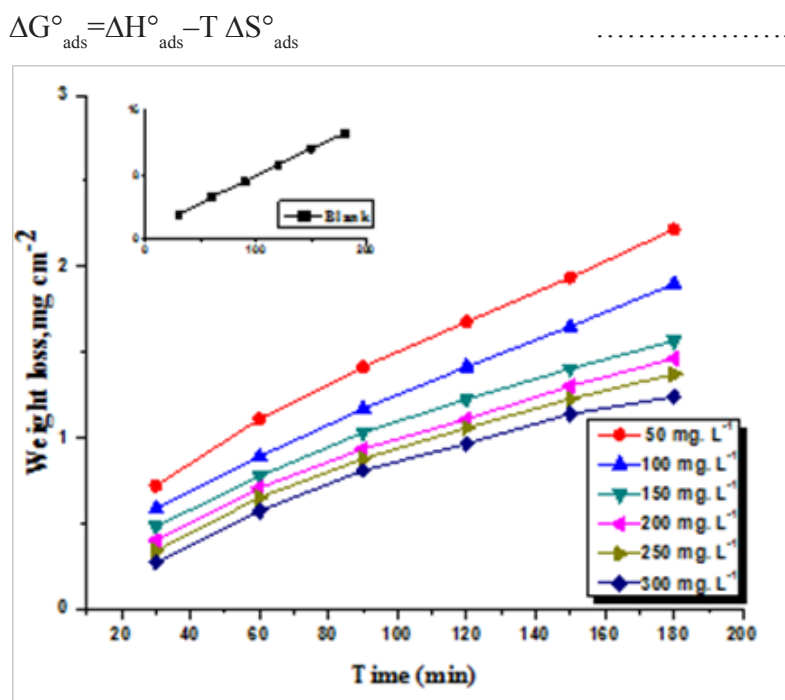

Figure I Immersion time vs MR for CS dissolution in $0.5 \mathrm{~mol} \mathrm{~L}^{-1} \mathrm{H}_{2} \mathrm{SO}_{4}$

\begin{tabular}{|c|c|c|c|c|c|c|c|c|}
\hline$\left[C_{i n h}\right]$ & $30^{\circ} \mathrm{C}$ & & $35^{\circ} \mathrm{C}$ & & $40^{\circ} \mathrm{C}$ & & $45^{\circ} \mathrm{C}$ & \\
\hline mg. L-1 & CR & $\%$ IE & CR & \%IE & CR & \%IE & CR & \%IE \\
\hline & $\times 10^{-5}$ & & $\times 10^{-5}$ & & $\times 10^{-5}$ & & $\times 10^{-5}$ & \\
\hline 0 & 76 & --- & 98 & --- & 133 & --- & 157 & --- \\
\hline 50 & 27 & 64 & 50 & 48 & 91 & 31 & 113 & 27 \\
\hline 100 & 18 & 75 & 33 & 66 & 65 & 51 & 89 & 42 \\
\hline 150 & 14 & 81 & 26 & 73 & 46 & 65 & 84 & 46 \\
\hline 200 & 12 & 84 & 22 & 77 & 39 & 71 & 72 & 56 \\
\hline 250 & 10 & 86 & 21 & 79 & 31 & 76 & 48 & 69 \\
\hline 300 & 8 & 88 & 13 & 86 & 21 & 83 & 32 & 79 \\
\hline
\end{tabular}
nonexistence and existence the $\mathrm{A}$. Judaica treatment extract at $25^{\circ} \mathrm{C}$.

Table 2 The influence of various doses of $A$. Judaica extract on the $\left(C_{R}\right)$ and (\%IE) of CS in solution $0.5 \mathrm{~mol} \mathrm{~L}^{-1} \mathrm{H}_{2} \mathrm{SO}_{4}$ at various temperatures

\section{Effect of temperature}

The temperature influence on protection efficiency was illustrated by transition-state and Arrhenius equations.

Transition state equation:

Rate $\left(\mathrm{k}_{\text {corr }}\right)=\mathrm{TR} / \mathrm{Nh} \mathrm{e}^{\left(-\Delta \mathrm{H}^{*} / \mathrm{RT}\right)} \mathrm{e}^{\left(\Delta \mathrm{S}^{*} / \mathrm{R}\right)}$ 
Arrhenius relation:

$\log \mathrm{k}_{\text {corr }}=$ constant $+\left(-\mathrm{E}_{\mathrm{a}}^{*} / 2.303 \mathrm{RT}\right)$

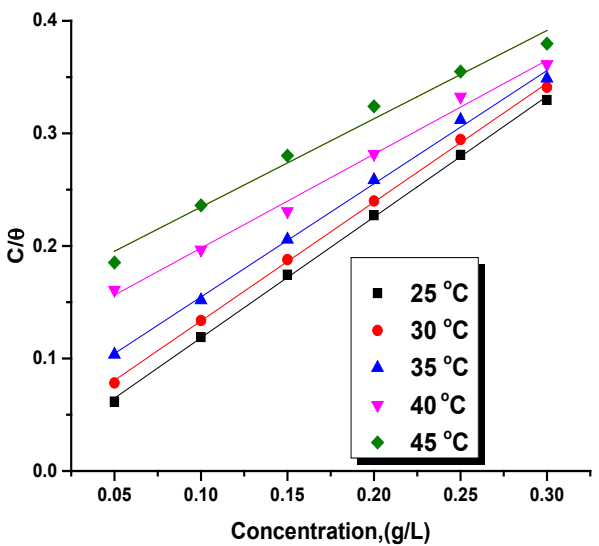

Figure 2 Langmuir diagrams for dissolution of CS in $0.5 \mathrm{~mol} \mathrm{~L}^{-1} \mathrm{H}_{2} \mathrm{SO}_{4}$ at various temperatures in nonexistence and existence of various doses of $\mathrm{A}$. Judaica.

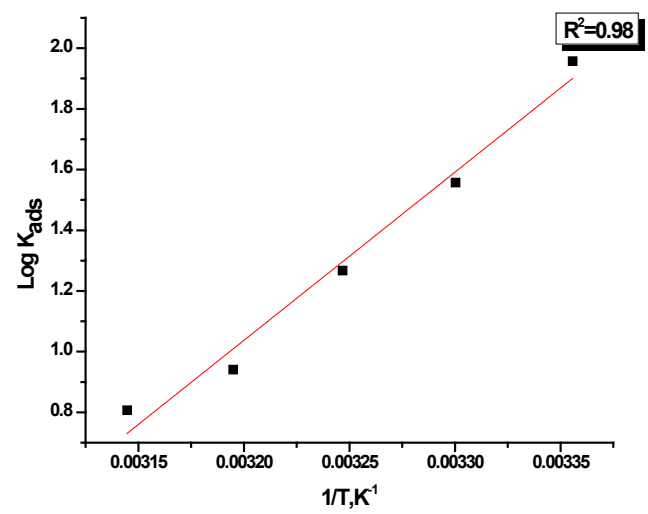

Figure $3(1000 / T)$ vs $\left(\right.$ Log $\left.\mathrm{K}_{\text {ads }}\right)$ diagrams for the CS dissolution in $0.5 \mathrm{~mol} \mathrm{~L}^{-}$ $\mathrm{H}_{2} \mathrm{SO}_{4}$ in presence of $A$. Judaica.

Table 3 Parameters for A. Judaica extract on surface of CS in $0.5 \mathrm{~mol} \mathrm{~L}^{-1}$ $\mathrm{H}_{2} \mathrm{SO}_{4}$ at different temperatures

\begin{tabular}{lllll}
\hline $\begin{array}{l}\text { Temp., } \\
\mathbf{K}\end{array}$ & $\begin{array}{l}\mathbf{K}_{\text {ads }} \\
\mathbf{M}^{-1}\end{array}$ & $\begin{array}{l}-\Delta \mathbf{G}^{\circ}{ }_{\text {ads }} \\
\mathbf{k J ~ m o l}{ }^{-1}\end{array}$ & $\begin{array}{l}-\Delta \mathbf{H}^{\circ}{ }_{\text {ads }} \\
\mathbf{~ k J ~ m o l} \mathbf{l}^{-1}\end{array}$ & $\begin{array}{l}-\Delta \mathbf{S}^{\circ}{ }_{\text {ads }} \\
\mathbf{2 9 8} \mathbf{l}^{-1} \mathbf{K}^{-1}\end{array}$ \\
$\mathbf{3 0 3}$ & 90.6 & 21.1 & & 35.2 \\
$\mathbf{3 0 8}$ & 36.1 & 19.1 & & 28.1 \\
$\mathbf{3 1 3}$ & 8.7 & 17.7 & 10.6 & 23.2 \\
$\mathbf{3 1 8}$ & 6.4 & 15.5 & & 17.5 \\
\hline
\end{tabular}

The mean data for the rate of corrosion $\left(\mathrm{k}_{\text {corr }}\right)$ given from MR tests at different temperatures was utilized to study the temperature effect. Depending on Arrhenius relation, the data of $1 / \mathrm{T}$ were drawn vs Log $\mathrm{k}_{\text {corr }}$. The outcome diagrams were straight lines with slopes $=$ (- $\left.\mathrm{E}_{\mathrm{a}}^{*} / \mathrm{R} 2.303\right)$, from which $\mathrm{E}_{\mathrm{a}}^{*}$ can be measured. The same behavior was given when drawing the data of $1 / \mathrm{T}$ vs. $\log \left(\mathrm{k}_{\text {corr }} / \mathrm{T}\right)$ as given in Figure 4, Figure 5. By the transition state relation, the intercept $=$
$\left[\left(\Delta \mathrm{S}^{*} / 2.303 \mathrm{R}\right)+(\log (\mathrm{R} / \mathrm{Nh})]\right.$, the slope $=\left(-\Delta \mathrm{H}^{*} / 2.303 \mathrm{R}\right)$ and from which the data of $\Delta \mathrm{H}^{*}$ and $\Delta \mathrm{S}^{*}$ were found and recorded in Table 4.The outcome data lead to $\mathrm{E}_{\mathrm{a}}^{*}$ improve in attendance of extract than in its nonexistence. i.e. the molecules of extract physically adsorbed on surface of CS. By temperature improving the lowering \% IE due to desorption of extract molecules from the CS surfaces. The analysis of parameters give $\mathrm{E}_{\mathrm{a}}^{*}$ rise when the plant extract dose improve. The energy barrier of reaction corrosion rise, as outcome data, the rate of corrosion was decreased. However, the data interpretation of and $\left(\Delta \mathrm{H}^{*}\right)$ has + ve sign reflect the nature endothermic of dissolution of $\mathrm{CS}$ in sulfuric acid. $\Delta \mathrm{S}^{*}$ data is suitable to nonexistence and existence acid solution are negative. This indicate that the activated complex, in the step of rate determining, associated by dissociation rather than accumulation, i.e., rise dis-ordering happens on going from reactants to the activated complex. ${ }^{18}$

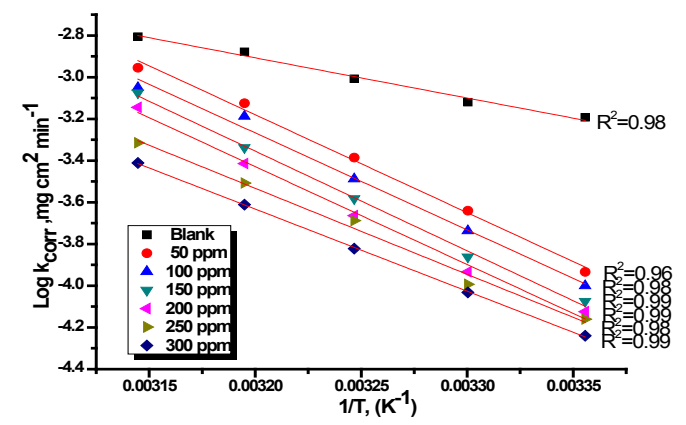

Figure 4 Plots I/T vs log kcorr for CS dissolution in $0.5 \mathrm{~mol} \mathrm{L-I} \mathrm{H2SO} 4$ in nonexistence and existence of various doses of $A$. Judaica extract.

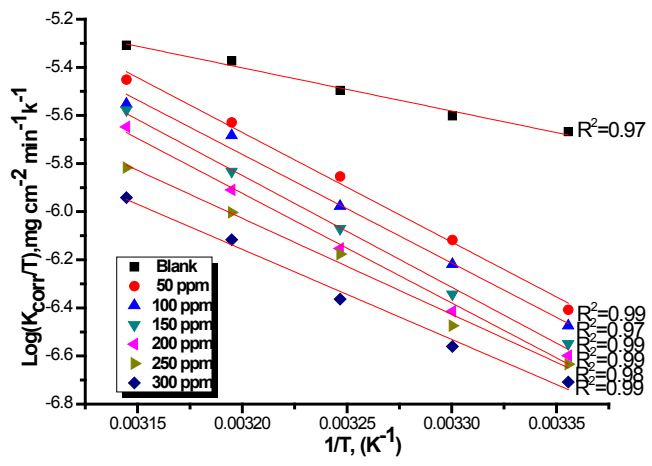

Figure 5 Diagrams $\left(\mathrm{I} / \mathrm{T}\right.$ vs $\left(\log \left(\mathrm{k}_{\text {corr }} / \mathrm{T}\right)\right)$ for CS corrosion in $0.5 \mathrm{~mol} \mathrm{L-1}$ $\mathrm{H}_{2} \mathrm{SO}_{4}$ in nonexistence and existence of various doses of $A$. Judaica extract.

Table 4 Parameters for CS dissolution in $0.5 \mathrm{~mol} \mathrm{~L}^{-1} \mathrm{H}_{2} \mathrm{SO}_{4}$ in nonexistence and existence of various doses of $A$. Judaica extract

\begin{tabular}{|c|c|c|c|}
\hline $\begin{array}{l}{\left[C_{i n h}\right]} \\
m g \cdot L^{-1}\end{array}$ & $\begin{array}{l}\mathrm{E}_{\mathrm{a}}^{*} \\
\mathrm{~kJ} \mathrm{~mol}^{-1}\end{array}$ & 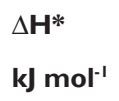 & $\begin{array}{l}-\Delta \mathbf{S}^{*} \\
\mathbf{J} \mathbf{~ m o l}^{-1} \mathbf{K}^{-1}\end{array}$ \\
\hline 0 & 51 & 34 & 191 \\
\hline 50 & 66 & 65 & 105 \\
\hline 100 & 69 & 76 & 68 \\
\hline 150 & 70 & 78 & 32 \\
\hline 200 & 73 & 79 & 31 \\
\hline 250 & 74 & 87 & 24 \\
\hline 300 & 76 & 89 & 21 \\
\hline
\end{tabular}




\section{Electrochemical measurements}

\section{PP methods}

The cathodic and anodic kinetic reactions were done by calculation from Tafel polarization (TP). Figure (6) given the addition of A. Judaica on cathodic and anodic polarization diagrams of CS in 0.5 mol L-1 $\mathrm{H}_{2} \mathrm{SO}_{4}$ in non existence and existence of various doses of A. Judaica extract. Both reactions were affected when the A. Judaica is added to the test solution. Addition of extract lowers both metal corrosion and evolution of hydrogen. Parameters from PP, i.e. $\left(\mathrm{E}_{\text {corr }}\right)$, $\left(\beta_{\mathrm{a}}, \beta_{\mathrm{c}}\right)$ and $\left(\mathrm{i}_{\text {corr }}\right)$ given from the polarization extrapolation diagrams, are recorded in Table 5. The area among linear section of anodic branch and cathodic of PP plots becomes larger when A. Judaica extract is added to the acid medium. ${ }^{19}$ The obtained data were listed in Table 5. The addition of the extract reduces both cathodic and anodic currents and the absence of any change in potential of corrosion. This extract A. Judaica plays as mixed kind inhibitor. The PP data were similar with those given from MR tests. $\theta$ and (\% IE) were measured from the equation below :

$$
\% \mathrm{IE}=\theta \times 100=100 \times[1-(\mathrm{i} / \mathrm{i})]
$$

Where $\mathrm{i}^{\circ}, \mathrm{i}$ are the data of corrosion current in nonexistence and existence of A. Judaica extract, continually.

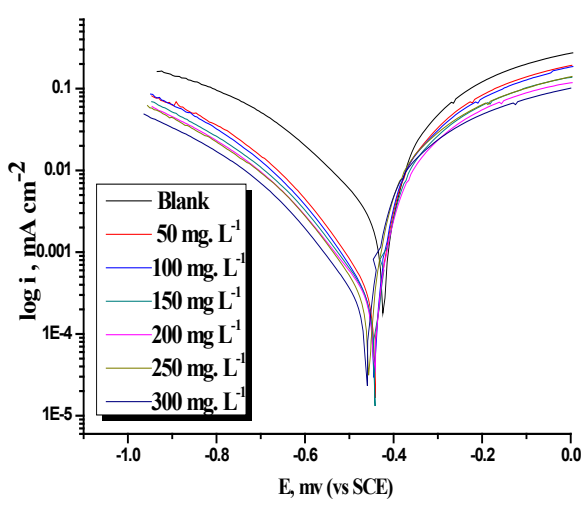

Figure 6 PP diagrams corrosion in $0.5 \mathrm{~mol} \mathrm{~L}^{-1} \mathrm{H}_{2} \mathrm{SO}_{4}$ in nonexistence and existence of various doses of $\mathrm{A}$. Judaica extract at $25^{\circ} \mathrm{C}$.

Table 5 PP value for corrosion of $\mathrm{CS}$ in $0.5 \mathrm{~mol} \mathrm{~L}^{-1} \mathrm{H}_{2} \mathrm{SO}_{4}$ in nonexistence and existence of various doses of $\mathrm{A}$. Judaica extract at $25^{\circ} \mathrm{C}$

\begin{tabular}{|c|c|c|c|c|c|c|c|}
\hline $\begin{array}{l}{\left[C_{i n h}\right]} \\
m g . L^{-1}\end{array}$ & $\begin{array}{l}\mathbf{i}_{\text {corr }} \\
\mu \mathrm{A} \\
\mathrm{cm}^{-2}\end{array}$ & $\begin{array}{l}-E_{\text {corr }} \\
m V\end{array}$ & $\begin{array}{l}\beta \mathrm{a}, \\
\mathrm{mV} \\
\mathrm{dec}^{-1}\end{array}$ & $\begin{array}{l}\beta c, \\
\mathrm{mV} \\
\text { dec }^{-1}\end{array}$ & $\begin{array}{l}\mathbf{k}_{\text {corr }} \\
\text { mpy }\end{array}$ & $\theta$ & IE\% \\
\hline 0 & 1870 & 422 & 67 & 168 & 853 & -- & -- \\
\hline 50 & 28 & 443 & 42 & $|4|$ & 135 & 0.847 & 84.7 \\
\hline 100 & 273 & $44 I$ & 34 & 135 & 130 & 0.854 & 85.4 \\
\hline 150 & 248 & 443 & 33 & $12 \mid$ & 124 & 0.867 & 86.7 \\
\hline 200 & 238 & 455 & 39 & 120 & 120 & 0.873 & 87.3 \\
\hline 250 & 207 & 461 & 38 & 115 & 113 & 0.889 & 88.9 \\
\hline 300 & 186 & 455 & 35 & 118 & 94 & 0.9 & 90 \\
\hline
\end{tabular}

\section{EIS method}

The $C_{\mathrm{dl}}$ and $R_{\mathrm{ct}}$, parameters from EIS tests are written in Table 6.
Further, Figure 7-9 shows the Nyquist diagrams of CS in presence and absence of the extract. The nature semicircular of EIS plots led to that a process of charge transfer governs mainly the CS corrosion. ${ }^{20}$ The EIS curves can be obtained. This modeling simulation help to measure not only the resistance of solution $R_{s}$, but also this can also be useful to predict other important parameters such as the $R_{\mathrm{ct}}$ resistance charge transfer and the $C_{\mathrm{dl}}$ double layer capacitance.

Table 6 EIS parameters for CS corrosion in solution containing $0.5 \mathrm{~mol} \mathrm{~L}^{-1}$ $\mathrm{H}_{2} \mathrm{SO}_{4}$ at various doses of $\mathrm{A}$. Judaica extract

\begin{tabular}{|c|c|c|c|c|}
\hline $\begin{array}{l}{\left[C_{i n h}\right],} \\
m g \cdot L^{-1}\end{array}$ & $\begin{array}{l}\mathbf{R}_{\mathrm{ct}} \\
\mathrm{Ohm} \mathrm{cm}-2\end{array}$ & $\begin{array}{l}C_{d l}, \\
\mu F \mathrm{~cm}^{-2}\end{array}$ & $\theta$ & $\%$ IE \\
\hline 0 & 6 & 226 & ---- & --- \\
\hline 50 & 34 & 67 & 0.795 & 79.5 \\
\hline 100 & 39 & 65 & 0.821 & 82.1 \\
\hline 150 & 44 & 60 & 0.843 & 84.3 \\
\hline 200 & 54 & 57 & 0.873 & 87.3 \\
\hline 250 & 71 & 48 & 0.902 & 90.2 \\
\hline 300 & 77 & 30 & 0.91 & 91 \\
\hline
\end{tabular}

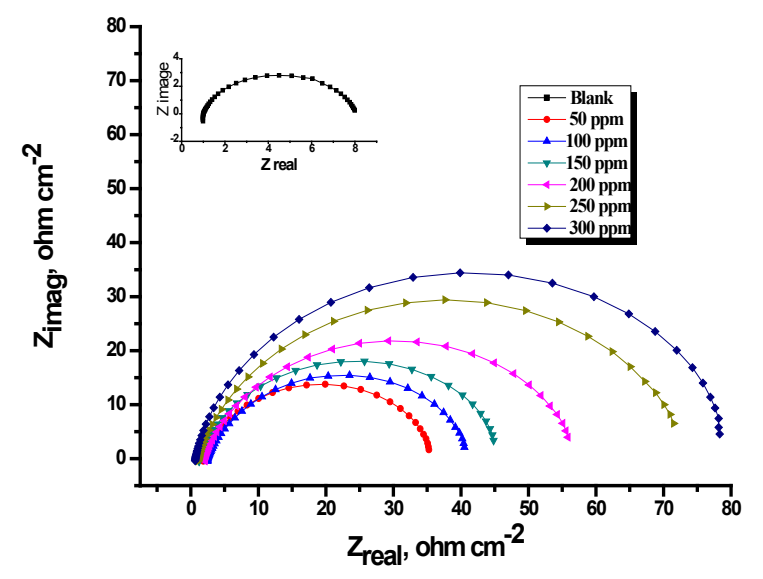

Figure 7 Nyquist diagrams of $\mathrm{CS}$ in $0.5 \mathrm{~mol} \mathrm{~L}^{-1} \mathrm{H}_{2} \mathrm{SO}_{4}$ in nonexistence and existence of various doses of $A$. Judaica.

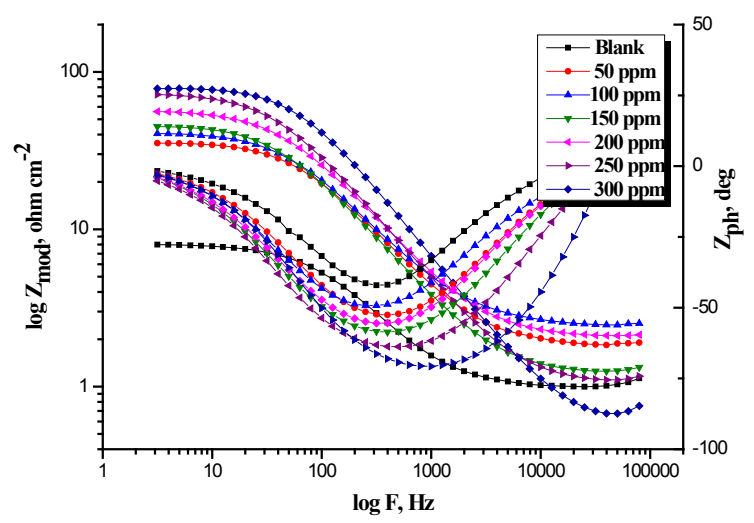

Figure 8 Bode diagrams of $\mathrm{CS}$ in $0.5 \mathrm{~mol} \mathrm{~L}^{-1} \mathrm{H}_{2} \mathrm{SO}_{4}$ in nonexistence and existence of various doses of $\mathrm{A}$. Judaica at $25^{\circ} \mathrm{C}$. 


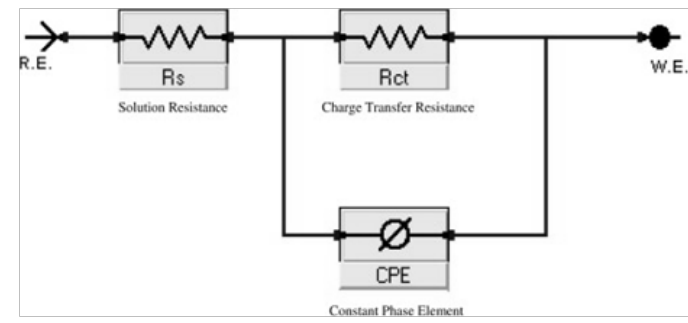

Figure 9 equivalent Circuit model for fitting impedance spectra.

The data $R_{\mathrm{ct}}$ were measured at various doses from the extract. The $R_{\mathrm{ct}}$ data is a measure of transfer electron occurs on surface of CS and it is inversely to the rate of corrosion. The $C_{\mathrm{dl}}$ was measured at the frequency $f_{\max }$ at which the maximal imaginary component utilized the following.

$$
C_{d l}=\frac{1}{2 \pi f_{\max } R_{c t}}
$$

The obtained data from EIS are recorded in Table 6. These data led to that the values of $R_{\mathrm{ct}}$ rise while that of $C_{\mathrm{dl}}$ decreased with the adding of various doses of A. Judaica to $0.5 \mathrm{~mol} \mathrm{~L}^{-1} \mathrm{H}_{2} \mathrm{SO}_{4}$. The lower in data of $C_{\mathrm{dl}}$ indicate that A. Judaica components are adsorbed at the surface of CS. The $C_{\mathrm{dl}}$ among the solution and the metal charged surface is regard as an electrical capacitor. The A. Judaica adsorption on surface of CS lower its electrical capacity with exchange the molecules of water indicating the performance of a coating layer of adsorption on the CS. The thickness of the coating layer $(d)$ is depending on $C_{\mathrm{dl}}$ in equivalent with model Helmholtz; obtain by the next equation:

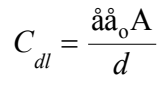

Where $\varepsilon=$ constant dielectric of the medium and $\varepsilon_{0}=$ free space permittivity $\left(8.854 \times 10^{-14} \mathrm{~F} \mathrm{~cm}^{-1}\right)$ and $A=$ the electrode area effective. From Table 6, addition of A. Judaica to the corrosive medium is found to lower the data of $C_{\mathrm{dl}}$ and also the minimum data was given for the A. Judaica with the maximum protection efficiency. The break down in $C_{\mathrm{dl}}$ data on rising doses of A. Judaica is due to the decrease of the surface blocked by the action of building layer adsorbed on interface surface among acidic medium and the surface of CS. The \%IE of A. Judaica for the CS corrosion in $0.5 \mathrm{~mol} \mathrm{~L}^{-1} \mathrm{H}_{2} \mathrm{SO}_{4}$ is measured utilized $R_{\mathrm{ct}}$ data as next:

$$
\% \mathrm{IE}=100 \mathrm{x} \theta=100 \times\left[1-\left(\mathrm{R}_{\mathrm{ct}}^{\circ} / \mathrm{R}_{\mathrm{ct}}\right)\right]
$$

\section{EFM tests}

Table 7 The peaks maximums were utilized to measure the current corrosion data lack prior information of Tafel slopes, and attendance only a lower polarization signal. ${ }^{21} \mathrm{CF}-2$ and $\mathrm{CF}-3$ measured from the EFM spectrum. Figure (10) give the spectra of EFM (frequency vs. current) of CS in solution $0.5 \mathrm{~mol} \mathrm{~L}^{-1} \mathrm{H}_{2} \mathrm{SO}_{4}$ including various doses of A. Judaica extract. The current of corrosion lower on improving the dose of A. Judaica extract, lead to this extract A. Judaica exhibit the CS corrosion in $0.5 \mathrm{~mol} \mathrm{~L}^{-1} \mathrm{H}_{2} \mathrm{SO}_{4}$ among a barrier film performance by adsorption on surface of $\mathrm{CS}$. The $\mathrm{CF}$ given under various test conditions are equal approximately to its data from theoretical ( 2 and 3) lead to the valid calculated value. The rise in dose of A. Judaica associated by an improving in the protection efficiency and the $\% \mathrm{IE}_{\mathrm{EFM}}$ was measured utilized by Eq. (12):

$$
\% \mathrm{IE}_{\text {EFM }}=\left[1-\left(\mathrm{i}_{\text {corr }} / \mathrm{i}_{\text {corr }}^{\circ}\right)\right] \times 100
$$

\begin{tabular}{|c|c|c|c|c|c|c|c|c|}
\hline $\begin{array}{l}{\left[C_{i n h}\right]} \\
m g \cdot L^{-1}\end{array}$ & $\begin{array}{l}i_{\text {corr }} \\
\mu \mathrm{A} \mathrm{cm}^{-2}\end{array}$ & $\begin{array}{l}\beta \mathrm{a} \\
\mathrm{mV} \mathrm{dec}^{-1}\end{array}$ & $\begin{array}{l}\beta c \\
m V \text { dec }^{-1}\end{array}$ & $\begin{array}{l}\mathbf{k}_{\text {corr }} \\
\mathrm{mpy}\end{array}$ & $C F(2)$ & CF(3) & $\theta$ & \%IE \\
\hline 0 & 2791 & 100 & 113 & 1275 & 1.8 & 3.1 & -- & -- \\
\hline 50 & 516 & 57 & 111 & 235 & 1.9 & 2.8 & 0.815 & 81.5 \\
\hline 100 & 471 & 56 & 108 & 215 & 1.9 & 2.9 & 0.831 & 83.1 \\
\hline 150 & 453 & 55 & 110 & 207 & 1.8 & 3.1 & 0.837 & 83.7 \\
\hline 200 & 402 & 58 & 108 & 183 & 1.9 & 2.8 & 0.856 & 85.6 \\
\hline 250 & 324 & 54 & 105 & 148 & 1.9 & 2.8 & 0.884 & 88.4 \\
\hline 300 & 271 & 50 & 99 & 127 & 2.1 & 2.8 & 0.903 & 90.3 \\
\hline
\end{tabular}

Where $i_{\text {corr }}$ and $i_{\text {corr }}^{\circ}$ are the corrosion currents in nonexistence and existence of A. Judaica extract

Table 7 EFM parameters for CS corrosion in $0.5 \mathrm{~mol} \mathrm{~L}^{-1} \mathrm{H}_{2} \mathrm{SO}_{4}$ including various doses of A. Judaica extract

\section{SEM tests}

Plate 1 illustrated the image given for CS coins after and before dipping into $0.5 \mathrm{~mol} \mathrm{~L}^{-1} \mathrm{H}_{2} \mathrm{SO}_{4}$ for half day, existence and nonexistence of additive $300 \mathrm{mg}^{-1}$ of A. Judaica. It can be given that the surface of CS suffers from severe corrosion in solution containing free acid. The CS surface is performed to be lower influence by the corrosive by utilized acid solution when encounter to solution $0.5 \mathrm{~mol} \mathrm{~L}^{-1}$ $\mathrm{H}_{2} \mathrm{SO}_{4}$ include $300 \mathrm{mg}$. L $\mathrm{L}^{-1}$ of A. Judaica extract. The CS morphology surface is smooth apparently parallel to the image given in the free acid case. However, a thin layer coating is performed and distributed randomly on surface of CS. This prove the addition of molecules of A. Judaica blocking the active site on CS, in turn, break down the contact among CS and the aggressive solution and sequentially give good characteristics for protection. ${ }^{22-28}$

\section{AFM tests}

AFM is a powerful tool to investigate the surface morphology of various samples at Nano-micro scale that is currently used to study the influence of corrosion inhibitors on metal solution interface. From 
the analysis, it can be gained regarding the roughness on the surface. The roughness profile values play an important role in identifying and report the efficiency of the inhibitor under study. Among the roughness take a role in explanation about the nature of the adsorbed film on the surface. ${ }^{28-35}$ Figure 11 shows the $3 \mathrm{D}$ images as well as elevation profiles of polished of carbon steel in absence and present of A. Judaica extract as an inhibitor. It observed in Figure 11 that the surface of CS specimen (a) exposed to corroded solution affected vales structure with large and deep crack but the surface (b) reveal that is covering film adsorbed on the metal surface. The conclusion, that the adsorption film can protect the surface of the metal from corrosion process. Analysis of the values indicated higher the values of roughness parameter reached. The mean roughness is found to be $(993.76 \mathrm{~nm})$ for the blank in acid solution which placed in $0.5 \mathrm{~mol} \mathrm{~L}^{-1}$ $\mathrm{H}_{2} \mathrm{SO}_{4}$ for $12 \mathrm{hrs}$. and analyzed. The observation of the metal surface which immersed in $0.5 \mathrm{~mol} \mathrm{~L}^{-1} \mathrm{H}_{2} \mathrm{SO}_{4}$ in presence of $300 \mathrm{mg}$. $\mathrm{L}^{-1}$ of extract inhibitor possess roughness $(303 \mathrm{~nm})$ compared to the blank solution and the roughness of free carbon steel $(17.46 \mathrm{~nm})$. It can be noted that the value is lower than that of the blank value. The decrease in the roughness value reflected the adsorption of extract molecules on metal surface thereby reducing the rate of corrosion.
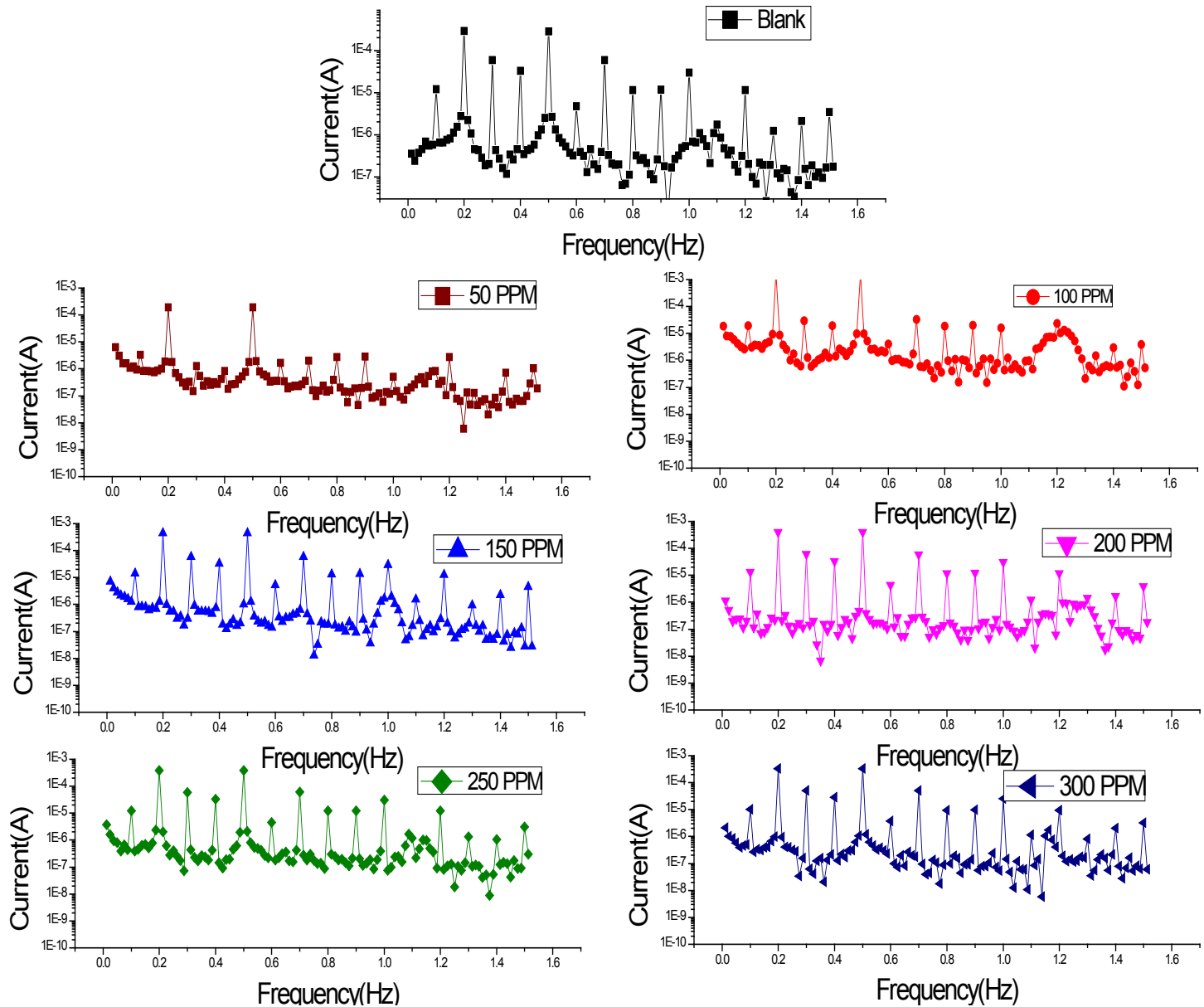

Figure $10 \mathrm{EFM}$ data for CS corrosion in $0.5 \mathrm{~mol} \mathrm{~L}^{-1} \mathrm{H}_{2} \mathrm{SO}_{4}$ in nonexistence and existence of A. Judaica extract at $25^{\circ} \mathrm{C}$.

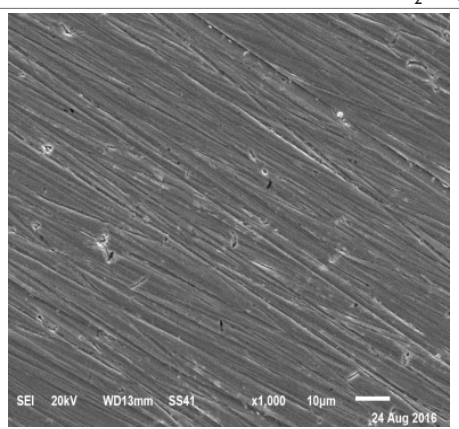

a) Carbon steel surface

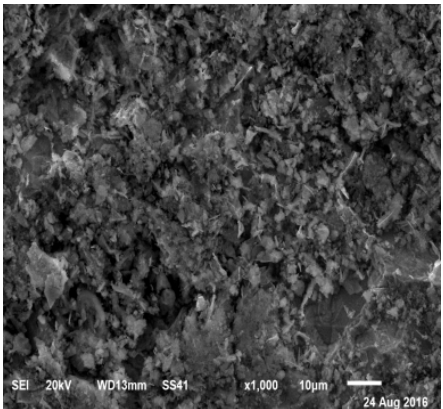

(b) Acid Free

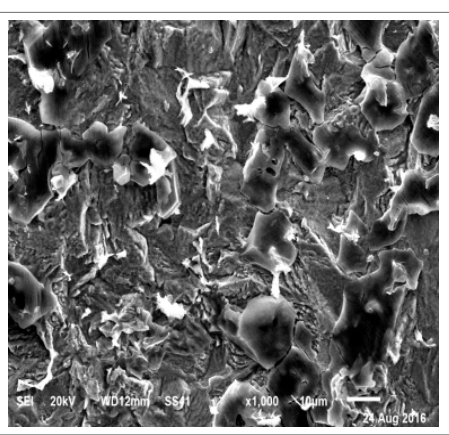

(c) 300 ppm of A. Judaica

Plate I (a-b-c) SEM Images of CS in solution $0.5 \mathrm{~mol} \mathrm{~L}^{-1} \mathrm{H}_{2} \mathrm{SO}_{4}$ a) CS, b) Acid Free and c) $300 \mathrm{mg}$. L $\mathrm{L}^{-1}$ of A. Judaica. 


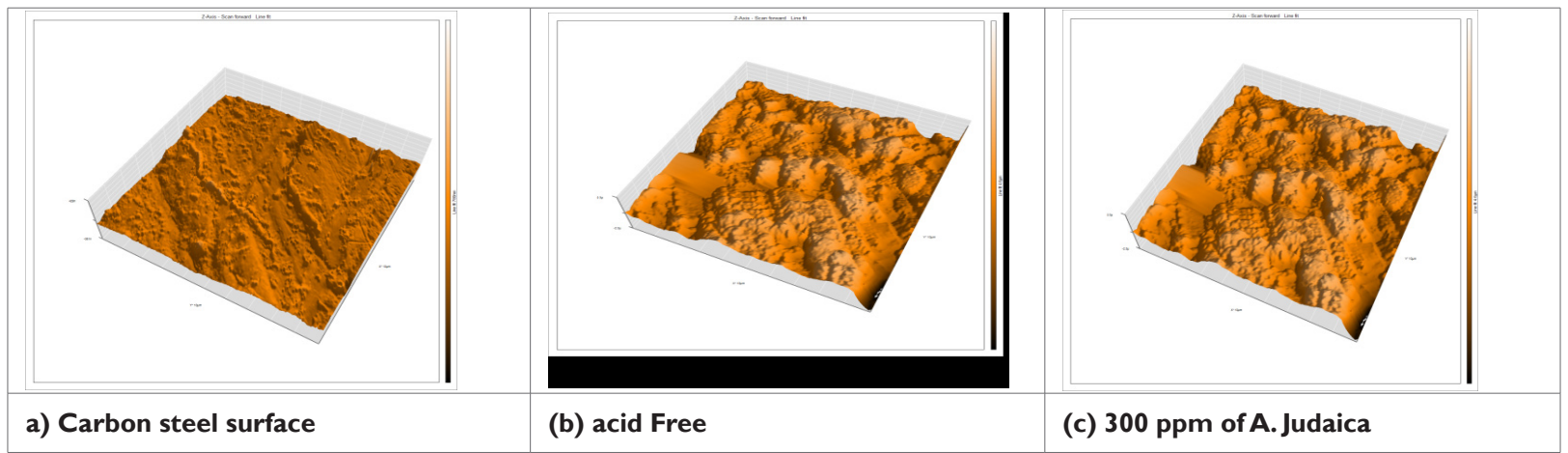

Figure II AFM analysis of CS in acidic solution a) free steel, b) $\mathrm{CS}$ in $0.5 \mathrm{~mol} \mathrm{~L}^{-1} \mathrm{H}_{2} \mathrm{SO}_{4}$ solution and c) in presence of $300 \mathrm{mg}$. $\mathrm{L}^{-1} \mathrm{~A}$. Judaica extract after immersion for 12 hrs.

\section{FTIR analysis of the extract and corrosion product}

Figures 12 represent the IR spectrum of A. Judaica extract and that of the film created on the carbon steel immersed in $0.5 \mathrm{~mol} \mathrm{~L}^{-1} \mathrm{H}_{2} \mathrm{SO}_{4}$, A. Judaica (300 mg. $\left.\mathrm{L}^{-1}\right)$. The FTIR spectrum of pure A. Judaica is given in Figures 12. The stretching -OH- frequency at $3361 \mathrm{~cm}^{-1}$, the stretching $-\mathrm{CH}$ frequency at $2942 \mathrm{~cm}^{-1}$, the stretching $\mathrm{C}=\mathrm{O}$ frequency appears at $1704 \mathrm{~cm}^{-1}$, the stretching $-\mathrm{C}=\mathrm{C}$ frequency appears at $(1405$ $\left.1547 \mathrm{~cm}^{-1}\right)$ (multiple bands), the -CN stretching frequency appears at $1246 \mathrm{~cm}^{-1}$ and the stretching -CO frequency appears at $1055 \mathrm{~cm}^{-1}$. The FTIR spectrum of the film formed on the CS inundation in 0.5 mol L-1 $\mathrm{H}_{2} \mathrm{SO}_{4}$ and A. Judaica $\left(300 \mathrm{mg}\right.$. $\left.\mathrm{L}^{-1}\right)$ is shown in Figures 12. The $-\mathrm{CH}$ stretching frequency shifts from $2942 \mathrm{~cm}^{-1}$ to $2933 \mathrm{~cm}^{-1}$. The stretching $\mathrm{C}=\mathrm{O}$ frequency shifts from $1704 \mathrm{~cm}-1$ to $1714 \mathrm{~cm}^{-1}$. The stretching $-\mathrm{C}=\mathrm{C}$ frequency shifts from $1405 \mathrm{~cm}^{-1}$ to $1425 \mathrm{~cm}^{-1}$. The stretching - $\mathrm{CN}$ frequency shifts from $1246 \mathrm{~cm}^{-1}$ to $1284 \mathrm{~cm}^{-1}$. The stretching -CO frequency shifts from $1055 \mathrm{~cm}^{-1}$ to $1042 \mathrm{~cm}^{-1} .36-39$

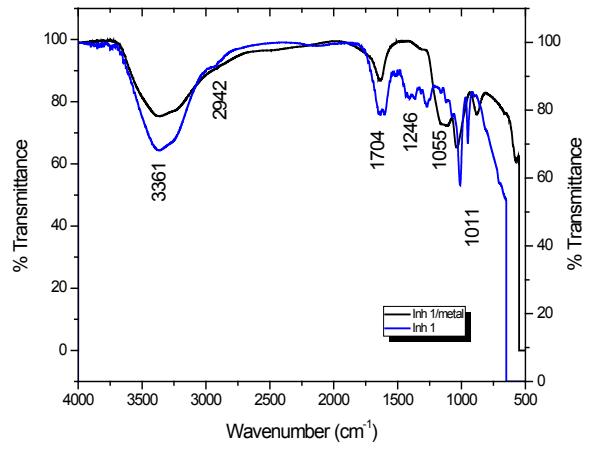

Figure I 2 FTIR spectra of the film created on the CS immersed in $0.5 \mathrm{~mol} \mathrm{~L}^{-1}$ $\mathrm{H}_{2} \mathrm{SO}_{4}+300 \mathrm{mg}$. L'-1 A. Judaica

\section{Mechanism of inhibition}

Since A. Judaica include a maximum capacity of kaempferol $O$-glycosides flavones (mono- and di-) lactone, terpenoidal vulgarin assembled, artemetin derivatives, tiliroside and taraxerol acetate. These molecules were found onto CS surface. This confirms the adsorption of these components of the extract on CS surface. These adsorbed molecules give a physical barrier among the corrosion medium and metal, thereby lowering aggressive attack of acidic medium and metal surface protecting by film coating. A. Judaica extract given a maximum protection because the higher degree of surface coverage resulting from the molecules adsorbed on the metal surface..$^{40-45}$

\section{Conclusion}

The excellent agree with all obtained data given from various tests led to A. Judaica can be utilized as an effective inhibitor in solutions of sulfuric acid. The \% IE improved with raising the plant extract dose, but break down with improving the solution temperature. The $\Delta \mathrm{G}^{\circ}{ }_{\text {ads }}, \Delta \mathrm{H}^{\circ}{ }_{\text {ads }}, \Delta \mathrm{S}^{\circ}$ ads of adsorption lead to that the adsorption is spontaneous and exothermic. The performance of phytochemical of the extract adsorbed on CS surface and formed a protective film by physical adsorption. $\mathrm{E}_{\mathrm{a}}^{*}$ value rises as the dose of A. Judaica improved. However, the nature endothermic of the corrosion of CS process can be given from enthalpy data. In appending, the activation entropy improved with raised dose of extract; hence, the system disorder is raised.

\section{Acknowledgements}

None.

\section{Conflict of interest}

The author declares no conflict of interest.

\section{References}

1. Fekry AM, Mohamed RR. Acetyl thiourea chitosan as an eco-friendly inhibitor for mild steel in sulfuric acid medium. Electrochim Acta. 2010;55(6):1933-1939.

2. Wang HL, Liu RB, Xin J. Considerations on reproducibility of potential and corrosion rate measurements in reinforced concrete. Corros Sci. 2004;46(10):2455-2466.

3. Lalitha A, Ramesh S, Rajeswari S. Surface protection of copper in acid medium by azoles and surfactants. Electrochim Acta. 2005;51(1):47-55.

4. Awad MI. Eco friendly corrosion inhibitors: Inhibitive action of quinine for corrosion of low carbon steel in $1 \mathrm{M} \mathrm{HCl} J$ Appl Electrochem. 2006;36(10):1163-1168.

5. Anthony N, Malarvizhi E, Maheshwari P, et al. Corrosion inhibition by caffeine -Mn. 2+ system. Indian J Chem Technol. 2004;11(3):346-350.

6. Ben Abdellah M, Hammouti B. Corrosion behavior of steel in concentrated phosphoric acid solutions. Appl Surf Sci. 2005;252(5):1657-1661.

7. Elouafi M, Abed Y, Hammouti B, et al. Effect of acidity level on the corrosion of steel in concentrated $\mathrm{HCl}$ solutions. Ann. Chim Sci Mater. 2001;26(5):79-84.

8. Abed Y, Hammouti B. Corrosion of steel in concentrated $\mathrm{H}_{2} \mathrm{SO}_{4}$ solutions. Bull Electrochem. 2000;16(7):296-298. 
9. Weina Su, Yimei Tian, Sen Peng. The influence of sodium hypochlorite biocide on the corrosion of carbon steel in reclaimed water used as circulating cooling water. Appl Surf Sci. 2014;315(1):95-103.

10. El-Etre AY. Khillah extract as inhibitor for acid corrosion of SX 316 steel. Appl Surf Sci. 2006;252(24):8521-8525.

11. Oguzie EE. Corrosion inhibition of aluminum in acidic and alkaline media by Sansevieriatrifasciata extract. Corros Sci. 2007;49(3):15271539 .

12. Fouda AS, Nofal AM, El-Ewady GY, et al. Eco-friendly impact of rosmarinus officinalis as corrosion inhibitor for carbon steel in hydrochloric acid solutions. Der Pharma Chemica. 2015;7(5):183-197.

13. Fouda AS, El-Awady GY, Abousalem AS. Corrosion Inhibition and Thermodynamic Activation Parameters of Arcatium Lappa extract on Mild Steel in Acidic Medium. Chem Sci Rev Lett. 2014;3(12):1277-1290.

14. Yan Li, Zhao P, Liang Q. Berberine as a natural source inhibitor for mild steel in $1 \mathrm{M} \mathrm{H}_{2} \mathrm{SO}_{4}$. Appl Surf Sci. 2005;252(5):1245-1253.

15. Zucchi F, Omar IH. Plant extracts as corrosion inhibitors of mild steel in HCl solutions. Surf Tech. 1985;24(4):391-399.

16. Mabry TJ, Markham KR, Thomas MB. The systematic identification of flavonoids. Springer-Verlag. 1970;15:41-164.

17. Harborne JB, Mabry TJ. The flavonoids: advances in researches, Chapter 2. Chapman and Hall Ltd, London, 1982.

18. Saleh NAM, El-Negoumy SI, Bou-Zaid MM. Flavonoids of Artemisia Judaica, A. monosperma and A. herba-alba. Photochemistry. 1987;26(11):3059-3064

19. Elgamal MHA, Ouf SA, Hanna AG, et al. Photochemical and mycological investigation of Artemisia monosperma. Folia Microbiol. 1997;42(3):203-210.

20. Khaled KF. Application of electrochemical frequency modulation for monitoring corrosion and corrosion inhibition of iron by some indole derivatives in molar hydrochloric acid. Mater Chem Phys. 2008;112(1):290-300

21. Khaled KF. Evaluation of electrochemical frequency modulation as a new technique for monitoring corrosion and corrosion inhibition of carbon steel in per chloric acid using hydrazine carbodithioic acid derivatives. $J$ Appl Electrochem. 2009;39(3):429-438.

22. Bosch RW, Hubrecht J, Bogaerts WF. Mobile Hydrogen Monitoring in the Wall of Hydrogenation Reactors. Corrosion. 2001;57(1):60-71.

23. Abdel-Rehim SS, Khaled KF, Abd-Elshafi NS. Electrochemical frequency modulation as a new technique for monitoring corrosion inhibition of iron in acid media by new thiourea derivative. Electrochim Acta. 2006;51(16):3269-3277.

24. Şahin M, Bilgiç S, Yilmaz H. The inhibition effects of some cyclic nitrogen compounds on the corrosion of the steel in $\mathrm{NaCl}$ mediums. Appl Surf Sci. 2002;195(1-4):1-7.

25. Schorr M, Yahalom J. The significance of the energy of activation for the dissolution reaction of metal in acids. Corros Sci. 1977;12(11):867-868.

26. Tang L, Lie X, Si Y. The synergistic inhibition between 8hydroxyquinoline and chloride ion for the corrosion of cold rolled steel in 0.5 mol L-1sulfuric acid. Mater Chem Phys. 2006;95(1):29-38.

27. Maayta AK, Al-Rawashdeh NAF. Inhibition of acidic corrosion of pure aluminum by some organic compounds. Corros Sci. 2004;46(5):11291140 .
28. Abboud Y, Abourriche A, Saffaj T. A novel azo dye, 8-quinolinol-5azoantipyrine as corrosion inhibitor for mild steel in acidic media. Desalination. 2009;237(1-3):175-189.

29. Khamis E. The effect of temperature on the acidic dissolution of steel in the presence of inhibitors. Corrosion. 1990;46(6):476-484.

30. Benabdellah M, Aouniti A, Dafali A. Investigation of the inhibitive effect of triphenyltin 2-thiophene carboxylate on corrosion of steel in $2 \mathrm{M}$ $\mathrm{H}_{3} \mathrm{PO}_{4}$ solutions. Appl Surf Sci. 2006;252(23):8341-8347.

31. Khaled KF, Samardzija KB, Hackerman N. Piperidines as corrosion inhibitors for iron in hydrochloric acid. $J$ Appl Electrochem. 2004;34(7):697-704.

32. Singh AK, Singh AK, Ebenso EE. Inhibition Effect of Cefradine on Corrosion of Mild Steel in $\mathrm{HCl}$ Solution. Int $J$ Electrochem Sci. 2014;9:352-364.

33. Morad MS, El-Dean AK. 2, 2'-Dithiobis (3-cyano-4, 6dimethylpyridine): A new class of acid corrosion inhibitors for mild steel. Corrosion science. 2006;48(11):3398-3412.

34. Singh AK, Quraishi MA. Piroxicam: A novel corrosion inhibitor for mild steel corrosion in $\mathrm{HCl}$ acid solution. J Mater Environ Sci. 2010;1(2):101110

35. Arab ST, Al-Turkustani AM. Corrosion inhibition of steel in phosphoric acid by phenacyldimethylsulfonium bromide and some of its psubstituted derivatives. Port Electrochim Acta. 2006;24:53-69.

36. Elewady GY. Pyrimidine derivatives as corrosion inhibitors for carbon steel in 2M hydrochloric acid solution. Int J Electrochem Sci. 2008;3(9):1149-1161.

37. Ahamad I, Prasad R, Quraishi MA. Thermodynamic, electrochemical and quantum chemical investigation of some Schiff bases as corrosion inhibitors for mild steel in hydrochloric acid solutions. Corros Sci. 2010;52(3):933-942.

38. Kus E, Mansfeld F. Anevaluation of the electrochemical frequency modulation (EFM) technique. Corros Sci. 2006;48(4):965-979.

39. Caigman GA, Metcalf SK, Holt EM. Thiophene substituted dihydropyridines. J Chem Cryst. 2000;30(6):415-422.

40. Muralidharan S, PhaniKLN, Pitchumani S, et al. PolyaminoBenzoquinone Polymers: A New Class of Corrosion Inhibitors for Mild Steel. J Electrochem Soc. 1995;142(5):1478-1483.

41. Prabhu RA, Venkatesha TV, Shanbhag AV. Inhibition effects of some Schiff's bases on the corrosion of mild steel in hydrochloric acid solution. Corros Sci. 2008;50(12):3356-3362.

42. Otmocic Curkovic H, Marusic K, Stupnisek-Lisac E, et al Electrochemical and AFM study of Corrosion Iinhibition with Respect to Application Method. Chem Biochem Eng Q. 2009;23(1):61- 66.

43. Pralhibh SB, Kotteeswaran P, Bheema Raju V. Study on the inhibition of MU steel Corrosion by Cationic Surfactant in $\mathrm{HCl}$ Medium. IOSR Journal of Applied Chemistry (IOSRJAC). 2012;2(5):45-53.

44. Armstrong RD, Hall CA. The corrosion of metals in contact with ester oils containing water at 60 and $150^{\circ}$ C. Electrochim Acta. 1995;40(9):11351147

45. Oguzie EE. Corrosion inhibitive effect and adsorption behavior of Hibiscus Sabdariffa extract on mild steel in acidic media. Port Electrochim Acta 2008;26(3):303-314 